\title{
Pharmacophore Based Screening \& Modification of Amiloride Analogs for targeting the NhaP-type Cation-Proton Antiporter in Vibrio cholerae
}

Mourin, $\mathrm{M}^{1^{*}}$, Bhattacharjee, A. ${ }^{2}$, Wai, A. ${ }^{1}$, Hausner, $\mathrm{G}^{1}$, O’Neil, J. ${ }^{3}$ and Dibrov. P. ${ }^{1}$

${ }^{1}$ Department of Microbiology, and ${ }^{3}$ Department of Chemistry, University of Manitoba

Winnipeg, Manitoba R3T 2N2 Canada

${ }^{2}$ Department of Biochemistry and Microbiology, North South University, Kuril - NSU Rd, Dhaka 1229, Bangladesh

*- corresponding author

Mailing address: Department of Microbiology, Faculty of Science, Rm. 430 Buller Building, University of Manitoba, Winnipeg, Manitoba R3T 2N2, Canada.

Phone: 1-204-333-6303. Fax: 1-204-474-7603. E-mail: muntahi.mourin@umanitoba.ca 


\section{Abstract}

The genome of Vibrio cholerae contains three structural genes for the NhaP-type cationproton antiporter paralogues, Vc-NhaP1, 2 and 3 mediating exchange of $\mathrm{K}^{+}$and or $\mathrm{Na}^{+}$for protons across the membrane. Based on phenotype analysis of chromosomal $V c$-NhaPl, 2 and 3 triple deletion mutants we suggested that Vc-NhaP paralogues might play a role in the Acid Tolerance Response (ATR) of $V$. cholerae as it passes through the gastric acid barrier of the stomach. Comparison of the biochemical properties of Vc-NhaP isoforms revealed that VcNhaP2 is the most active among all three paralogues. Therefore, Vc-NhaP2 antiporter is a plausible therapeutic target for developing novel inhibitors targeting these ion exchangers. Our structural and mutational analysis of $\mathrm{Vc}-\mathrm{NhaP} 2$ identified a putative cation binding pocket formed by antiparallel extended regions of two transmembrane segments (TMSs V/XII) along with TMS VI. Molecular Dynamics (MD) simulations suggested that the flexibility of TMSV/XII is crucial for the intra-molecular conformational events in Vc-NhaP2. In this study, we developed some putative Vc-NhaP2 inhibitors from Amiloride analogs (AAs). Amiloride is a potent inhibitor of human $\mathrm{Na}^{+} / \mathrm{H}^{+}$exchanger-1 (NHE1). Based on the pharmacokinetic properties and potential binding affinity scores we chose six AAs showing high binding affinity scores to Vc-NhaP2. In silico, the six AAs interacted with the functionally important amino acid residues located in TMSs III, IV, V, VI, VIIII and IX either from the cytoplasmic side (three AAs) or the periplasmic side (three AAs) of Vc-NhaP2. Four AAs were modified to reduce their toxicity profile compared to the original AAs. Molecular docking of the modified AAs revealed promising binding. The four selected drugs interacted with functionally important amino acid residues located on the cytoplasmic side of TMS VI, the extended chain region of TMS V and TMS XII and the loop region between TMSs VIIII and IX. Molecular dynamics simulations 
revealed that binding of the selected drugs destabilized the Vc-NhaP2 and altered the flexibility of functionally important TMS VI.

Key words: NhaP2-type cation-proton antiporter, Vibrio cholerae, Amiloride Analogs, Inhibitors against NhaP-type antiporters

\section{Introduction}

Vibrio cholerae, the causative agent of the diarrheal disease Cholera, is considered as an 'emerging and re-emerging' disease with epidemic and pandemic potentials [1-2]. V. cholerae has remarkable genetic features that enables the human pathogen to survive in different harsh environmental conditions [2]. In recent decades, this enteric pathogen has developed multi-drug resistance (MDR) by acquiring numerous mobile genetic elements [3]. In addition, a simulation based on an artificial neural network demonstrated that climate change might drastically elevate cholera outbreaks in the near future [4]. The combination of elevated outbreaks and higher prevalence of MDR $V$. cholerae could lead to an irrepressible situation. Unfortunately, oral vaccination for cholera only offers temporary prevention [5]. Therefore, the development of new antimicrobial treatments against this deadly pathogen is paramount.

$V$. cholerae is transmitted by a fecal-oral route; it is exposed to a wide range of environmental challenges and must adapt efficiently to changes in the ionic composition of its micro-surroundings [20]. In particular, after being ingested by humans it has to pass through the low $\mathrm{pH}$ and high potassium [6-7] stomach gastric acid barrier before reaching the small intestine for colonization and secretion of the cholerae toxin [8-11]. V. cholerae possesses an Acid Tolerance Response (ATR) to overcome and survive within this hostile environment [1218]. The genome of $V$. cholerae contains three NhaP paralogues, Vc-NhaP1, Vc-NhaP2 and 
NhaP3, which we extensively characterized biochemically as well as physiologically [12-18]. We reported that these NhaP paralogues primarily acted as $\mathrm{K}^{+}$or $\mathrm{Na}^{+} / \mathrm{H}^{+}$antiporters [12-18]. By carrying out phenotype analysis of engineered chromosomal $V c-n h a P 1, V c-n h a P 2$ and $V c-n h a P 3$ deletion mutants and complementation of each isoform, we proved that the three NhaP paralogues are essential for maintaining $\mathrm{K}^{+}$homeostasis in the cytoplasm of $V$. cholerae in vivo [13]. Expressed in trans, neither of the Vc-NhaP paralogues was able to complement the severe potassium-sensitive phenotype of the triple-deletion mutant completely. The apo- $V$. cholerae had much higher survival rate compared to the triple deletion mutant, Vc $\Delta$ NhaP123, when challenged by $\mathrm{HCl}(\mathrm{pH} 3.5)$ [13]. We therefore suggested that Vc-NhaP paralogues play a critical role in the Acid Tolerance Response (ATR) of $V$. cholerae as it passes through the gastric acid barrier of the stomach $[13,16]$. The Vc-NhaP type antiporters could be a potential target to develop druggable inhibitors to treat this deadly pathogen. Notably, these NhaP-type antiporters are phylogenetically diverse and abundant in the genomes of pathogenic microorganisms [19]. As a result, specific inhibitors against NhaP-type antiporters will potentially be less damaging to benign gut microflora compared to conventional antibiotics.

Vc-NhaP2 is the most active among the three Vc-NhaP1, 2 and 3 paralogues [13]. Based on mutagenesis experiments and in silico analyses, we have gathered extensive information on the structural, biological and functional properties of the Vc-NhaP2 antiporter [16-18]. The structural analysis of $\mathrm{Vc}-\mathrm{NhaP} 2$, based on the mutagenesis data, combined with the in silico structure modelling and Molecular Dynamics (MD) Simulations yielded two important elements in the organization of $\mathrm{Vc}-\mathrm{NhaP} 2$ : (1) a putative cation binding pocket formed by antiparallel extended regions of two transmembrane segments (TMSs V/XII) crossing each other in the 
middle of the membrane, and (2) a cluster of amino acid residues near the putative cationbinding pocket determining the ion selectivity $[16,18]$.

In this study, we developed putative druggable inhibitors against Vc-NhaP2 by modifying potential Amiloride analogs. Amiloride (AMLRD) was the first drug discovered to inhibit mammalian $\mathrm{Na}^{+} / \mathrm{H}^{+}$exchanger isoform 1 (NHE1) [21]. NHE1 and $\mathrm{Vc}-\mathrm{NhaP} 2$ belong to the cation/ proton antiport superfamily-1 (CPA-1) [12]. Additionally, AMLRD has been reported to be a bacteriostatic agent against different pathogenic bacteria [22]. This diuretic drug can affect the intracellular $\mathrm{Na}^{+}$and $\mathrm{K}^{+}$content of Streptococcus faecalis (in vitro) [23]. When these Streptococcus strains were treated with another pyrazine-containing potassium-sparing diuretic Triamterene, the antibacterial efficacies were similar [22]. However, for Gram-negative Pseudomonas, modified AMLRD analogues were more potent than AMLRD [24].

Here, we retrieved and developed AMLRD analogues by virtual screening and rational drug design. After implementing molecular docking and MD simulations, we predict the biological consequences of the interacting AMLRD analogues. To accomplish this, we screened forty-five AMLRD analogs based on their pharmacophore-based toxicity and ADME (adsorption, distribution, metabolism, excretion) properties. Six potential AMLRD analogs were selected based on their calculated binding affinity with Vc-NhaP2. In silico, the six AMLRD analogs interacted with the functionally important amino acid residues located in TMSs III, IV, V, VI, VIIII and IX either from the cytoplasmic side or the periplasmic side of Vc-NhaP2. Three AMLRD analogs were further modified to reduce their toxicity profiles compared to the parent compound. The dynamics of the Vc-NhaP2 were further analysed by carrying Molecular Dynamics (MD) simulations and the effect on flexibility and the rigidity of the protein upon drug binding was studied. Based on our analysis we have proposed three modified drugs along with 
one original AMLRD analog that can be potentially used as druggable inhibitors against VcNhaP2.

\section{Results}

\subsection{Screening, modifications and pharmacoinformatic exploration of the potential} amiloride analogs

Amiloride is a renowned diuretic capable of inhibiting cationic antiporters in various mammalian cells [22, 26-27]. Forty-five chemical structures similar to AMLRD along with their Canonical SMILES and PubChem CID were initially collected from the PubChem database. For investigating ADMET properties, the values from the pkCSM server were mostly prioritized since this server uses a novel approach called graph-based signatures which outperforms other available tools [28]. Data obtained from ProTox-II, OSIRIS Property Explorer and admetSAR 2.0 were also compiled in Excel spread sheets to compare the overall pharmacokinetics properties of the obtained compounds (Supplementary Excel File).

After analyzing the ADMET and QSAR properties, the three least toxic compounds $(3,5-$ diamino-6-chloro-N-cyanopyrazine-2-carboxamide (PubChem CID: 123478999), 3-amino-Ncarbamimidoyl-6-chloro-5-(dimethylamino)pyrazine-2-carboxamide ～(PubChem CID: 137630036) and 5-amino-6-chloro-N-(diaminomethylidene)-3-[ethyl(propan-2yl)amino]pyrazine-2-carboxamide (PubChem CID: 11174068)) were selected as lead compounds (Figure 1, Table 1 and 2). These three drugs showed the most favorable absorption, metabolism, bioavailability and toxicity properties (Tables 1 and 2). However, 3,5-diamino-6-chloro-Ncyanopyrazine-2-carboxamide (PubChem CID: 123478999) and 3-amino-N-carbamimidoyl-6chloro-5-(dimethylamino) pyrazine-2-carboxamide (PubChem CID: 137630036) showed active mutagenicity in Pro-Tox II analysis (Table 1). These two drugs were further modified to lower 
their toxicities and improve their pharmacokinetic properties as described in Materials and Methods. The designed drugs were named as Amiloride for cholera or 'AmiKol'. Hence, Amikol 1, Amikol 2 and Amikol 3 (Figure 1, Tables 1, 2 and 3). The newly modified drugs have much lower toxicity profiles than the original analogs (Table 1).

\subsection{Quality of the Vc-NhaP2 antiporter structure}

The generated structure of Vc-NhaP2 has 13 Transmembrane Segments (TMSs) with TMSs V and XII being discontinuous; TMSs V and XII have extended chain region that cross each other in the middle of the membrane $[16,18]$ (Supplementary Figure 1). The discontinuous region is highly flexible and crucial for the functioning of the antiporter $[16,18]$. The ion binding amino acid residues are mainly located in the flexible region between TMSs V, XII and TMS VI $[16,18]$

The final refined model of the Vc-NhaP2 channel has a MolProbity score of 0.71 with a 0 clash score and 0 bad bonds (Table 4). Moreover, $98 \%$ of residues are located in the favored region of Ramachandran plot (Fig 2). The MolProbity score is a single number representing the one number that reflects the crystallographic resolution at which those values would be expected. The Molprobity score of 0.71 indicates that the refined model is of a quality typically observed for high-resolution crystal structures deposited in the protein data bank with a resolution of 0.71 A. (Table 4). The same conclusion was reached independently by ProSA-web [40] analysis that yielded a Z-score of -6.71 using only the C- $\alpha$ atoms of the input structure (Figure $3 \mathrm{~A}$ ). The negative Z-score value indicates that the overall model quality contained less error than typically found for native proteins of similar size as examined by X-ray diffraction. The residue score plot 
in Figure $3 \mathrm{~B}$ shows negative energies as a function of amino acid sequence throughout the protein indicating few poorly defined regions in the refined Vc-NhaP2 structure (Figure 3B).

\subsection{Molecular interactions between Vc-NhaP2 and selected drug candidates}

Interactions between $\mathrm{Vc}-\mathrm{NhaP} 2$ and the six nominated drug compounds reveal two potential drug-binding sites in the antiporter. One binding site is located on the periplasmic side of the protein and the other is on the cytoplasmic side. 3-amino-N-carbamimidoyl-6-chloro-5(dimethylamino) pyrazine-2-carboxamide (PubChem CID 137630036), AmiKol 1 and 5-amino6-chloro-N-(diaminomethylidene)-3-[ethyl(propan-2-yl)amino]pyrazine-2-carboxamide

(PubChem CID 11174068) show potential binding at the amino acid residues located at the cytoplasmic region of TMSs IV, V and X. ADV and Achilies showed average binding affinity scores of $-5.9 \mathrm{kcal} / \mathrm{mol},-6 \mathrm{kcal} / \mathrm{mol}$ and $-5.3 \mathrm{kcal} / \mathrm{mol}$ respectively for these three drugs (Figure 4). Noticeably, except AmiKol 1, all the drugs interacted with the protein through hydrogen bonding. Residues such as Arg 79, Phe 138, Ser 139 and Asp 273 interacted mostly with all the drugs (Table 2). These residues made hydrophobic interactions with the ligands (except the $-\mathrm{OH}$ group of Ser 139 that interacted with 3-amino-N-carbamimidoyl-6-chloro-5(dimethylamino)pyrazine-2-carboxamide via a H-bond).

In Vc-NhaP2, Asp 273 located in TMS X, is involved in maintaining the ion selectivity of the antiporter $[16,18]$ since mutating it to Ala 273 makes the antiporter only selective for $\mathrm{K}^{+}$ whereas no activity is observed with $\mathrm{Na}^{+}[16,18]$. Ala 135 in TMS V and Glu 155 in TMS VI are also involved in interactions with the ligands (Figure 4, Table 2). Interestingly, Ala 135 is present near the TD motif (Thr 132 and Asp 133) [16, 18]; the TD motif is essential for the functioning of the $\mathrm{Vc}-\mathrm{NhaP} 2$ antiporter because this motif is present in the extended region of 
TMS V and is involved in direct cation binding $[16,18]$. We showed that Glu 155 in TMS VI is directly involved in forming the cation-binding pocket along with the other amino acids present in TMS VI (e.g., Asn 161, Glu 162 and Ser 156) [16, 18]. These interactions between the amino acid residues present in the protein and the ligands would likely interfere with the function of TMSs V, VI and TMS X, since these TMSs are located in close proximity in the threedimensional structure of the protein (Supplementary Figure 1).

3,5-diamino-6-chloro-N-cyanopyrazine-2-carboxamide (PubChem CID 123478999), AmiKol 2 and Amikol 3 showed potential binding at the periplasmic side of Vc-NhaP2 with average binding affinities of $-5.0 \mathrm{kcal} / \mathrm{mol}(\mathrm{ADV}),-7.3 \mathrm{kcal} / \mathrm{mol}(\mathrm{ADV})$ and $-6.033 \mathrm{kcal} / \mathrm{mol}(\mathrm{ADV})$. Six amino acid residues Asn 66, Val 170, Phe 236, Asn 240, Ser 245, Ile 247, Gly 244, Phe 353 interact with all the three ligands (Figure 4). Among them Val 170, Phe 236, Ile 247 and Gly 244 make hydrophobic interactions. The $\mathrm{OH}$ group of Ser 245 forms H-bonds with 3,5-diamino-6chloro-N-cyanopyrazine-2-carboxamid, Amikol 1 and 2. Asn 66 and Asn 240 make both hydrophobic and H-bonding with the ligands. However, Asn 240 uses the carbonyl group of the backbone to create a H-bond with Amikol 2. These amino acid residues are conserved in the other NhaP-type antiporters [15] and are present in TMSs IV, VI, X, XI, XII and XIII. The biological functions of these amino acid residues are still not clear.

\subsection{Root Mean Square Deviation (RMSD) of backbone C- $\alpha$ carbon}

MD simulations were carried out with the four selected docked complex structures and compared to the apo- Vc-NhaP2 structure to measure the dynamics and stabilities of the drugbound complexes (Figures 5 and 6). The dynamics of the protein were probed by determination of the RMSD's of backbone C- $\alpha$ carbon atoms for the apo- as well as the drug-bound-Vc-NhaP2 
complexes (Figure 5). The RMSD values indicate that the protein stability of the drug-bound complexes deviates from that of the apo-Vc-NhaP2 on the 1 microsecond timescale (Figure 5). The apo-Vc-NhaP2 is well stable after over the first 300 ns with an overall RMSD value of 0.4 nm (black line, Figure 5). Interestingly, the Amikol 2 (green line) and Amikol 3 (red line) drugbound complexes show significant fluctuations with average RMSD values of 0.6 and 0.5 , respectively (Figure 5). The 5-amino-6-chloro-N-(diaminomethylidene)-3-[ethyl(propan-2-yl) amino] pyrazine-2-carboxamide (PubChem ID 11174068) drug-bound complex (purple?) was stable with an RMSD value of $0.4 \mathrm{~nm}$ over $750 \mathrm{~ns}$, followed by a noticeable fluctuation with an RMSD value of $0.5 \mathrm{~nm}$. The Amikol 1-bound complex was stable with an RMSD of $0.3 \mathrm{~nm}$ over the 1 microsecond simulation period. (Blue line Figure 5).

\subsection{Root Mean Square Fluctuation (RMSF) backbone $\mathrm{C}-\alpha$ carbon}

Whereas the overall dynamics of the protein and the drug complexes are only slightly different a few areas of the protein show greatly increased dynamics upon drug binding. This is indicated in Figure 6 where the mobility and flexibility of the backbone C- $\alpha$ carbons of each amino acid residue is indicated from the root mean square fluctuation (RMSF) analysis (Figure 6). In the apo-Vc-NhaP2 higher fluctuations are noticeable in TMS IV (amino acid residue from 81V to $111 \mathrm{~L})$, TMS V (118L to $142 \mathrm{G}$ ) and TMS VII (333K to 350A, TMS XIII (362N to 379N) (Figure 6). The flexibility in TMSs V and VII is crucial for the ion transport of Vc-NhaP2 by the alternating-access mechanism [16], whereas TMS VI, containing the ion binding residues, remains rigid. Upon binding of Amiko-1, it greatly elevated dynamics are observed in TMS VI (149V to $176 \mathrm{G})$ compared to the apo-Vc-NhaP2 (Figure 6). The largest increase in the mobility of the amino acid residues (RMSF $>0.3 \mathrm{~nm}$ ) in TMS V and VI are visible in the Amikol 1-bound 
structure (Figure 6). These results clearly indicate an effect of the drug on the dynamics of the amino acid residues present in the functionally-important TMSs.

\section{Figure Legends}

Figure 1. Nominated Amiloride analogues for blocking the Vc-NhaP2 antiporter. (A) A, B and C are the original AMRLD analogs. (B) Designed drugs that have lower toxicity than their lead compound.

Figure 2. Ramachandran plots for a) General residues, b) Glycine, c) Pre-Proline and d) Proline residues for Vc-NhaP2. $98.8 \%$ of amino acids are in the favoured regions.

Figure 3. Z-score plot and plot of residue scores of the Vc-NhaP2 structure generated by Pro-SA web. (A) The Z-score value is displayed in a plot that contains the $\mathrm{z}$-scores of all experimentally-determined protein chains in the current PDB. In this plot, groups of structures from different sources (X-ray, NMR) are distinguished by different colors. The black dot indicates the position of Vc-NhaP2. (B) This plot shows local model quality by plotting energies as a function of amino acid sequence position $\mathrm{i}$. The plot is smoothed by calculating the average energy over each 40-residue fragment s $(i, i+39)$, which is then assigned to the 'central' residue of the fragment at position $i+19$ (thick line). A second line with a smaller window size of 10 residues is shown in the background of the plot (thin line).

Figure 4. Molecular interactions between Vc-NhaP2 and selected drug candidates. 3,5-diamino6-chloro-N-cyanopyrazine-2-carboxamide (PubChem CID123478999), AmiKol 2 (Modified 123478999) and AmiKol 3 (Modified 123478999) showed potential binding to periplasmic side of Vc-NhaP2. 3-amino-N-carbamimidoyl-6-chloro-5-(dimethylamino)pyrazine-2-carboxamide 
(PubChem CID 137630036), AmiKol 1 (Modified from 137630036) and 5-amino-6-chloro-N(diaminomethylidene)-3-[ethyl(propan-2-yl)amino]pyrazine-2-carboxamide (PubChem CID 11174068) showed potential binding to the cytoplasmic side of Vc-NhaP2. The amino acid residues in $\mathrm{Vc}-\mathrm{NhaP} 2$ that interacted with each drug are also labeled.

Figure 5. Time-dependent root mean square deviation (RMSD) of backbone C- $\alpha$ of the apo-VcNhaP2 and drug-bound complexes. The black color represents the apo-Vc-NhaP2. Blue, green, pink and purple colors represent AmiKol 2-, AmiKol 1-, Amikol 3- and PubChem CID 11174068- bound complexes, respectively.

Figure 6. The root-mean squared fluctuations (RMSF) for the C- $\alpha$ atoms of the backbone of the apo-Vc-NhaP2 and drug-bound complexes over an 1 microsecond timescale. The black color represents the apo-Vc-NhaP2. The blue, green, pink and purple colors represent AmiKol 2-, AmiKol 1- Amikol 3- and PubChem CID 11174068-bound complexes, respectively. 
Fig. 1A

$\mathbf{a}$<smiles>N#CNC(=O)c1nc(Cl)c(N)nc1N</smiles>

3,5-diamino-6-chloroN-cyanopyrazine-2carboxamide

PubChem CID: 123478999

\section{b}<smiles>CCN(c1nc(N)c(Cl)nc1C(=O)N=C(N)N)C(C)C</smiles>

5-amino-6-chloro- $N$ (diaminomethylidene)3-[ethyl(propan-2yl)amino]pyrazine-2carboxamide

PubChem CID: 11174068 c<smiles>CN(C)c1nc(N)c(C(=O)NC(=N)N)nc1Cl</smiles>

3-amino-N-carbamimidoyl6-chloro-5(dimethylamino)pyrazine-2carboxamide

PubChem CID: 137630036

Fig. 1B

\section{a}<smiles>CC(C)N(CCC(=O)O)c1nc(N)c(C(=O)NC(N)=[NH2+])nc1Cl</smiles>

\section{b}<smiles>N#CN(CCO)C(=O)c1nc(Cl)c(N)nc1N</smiles>

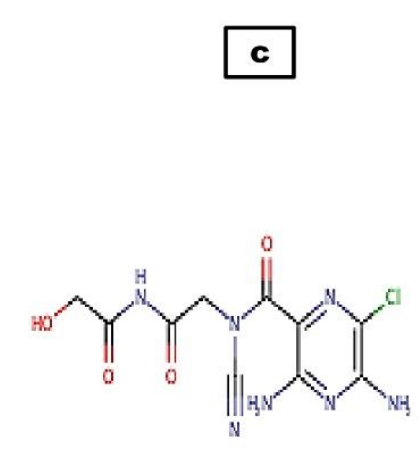


Fig. 2

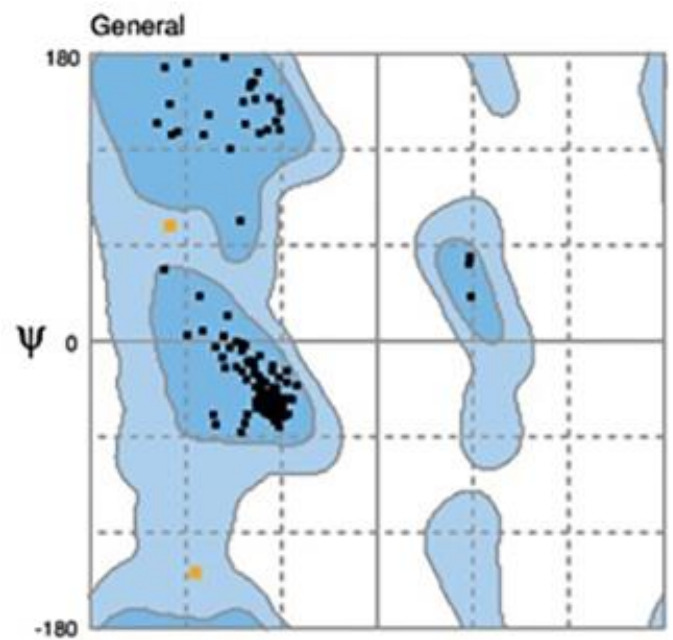

Glycine
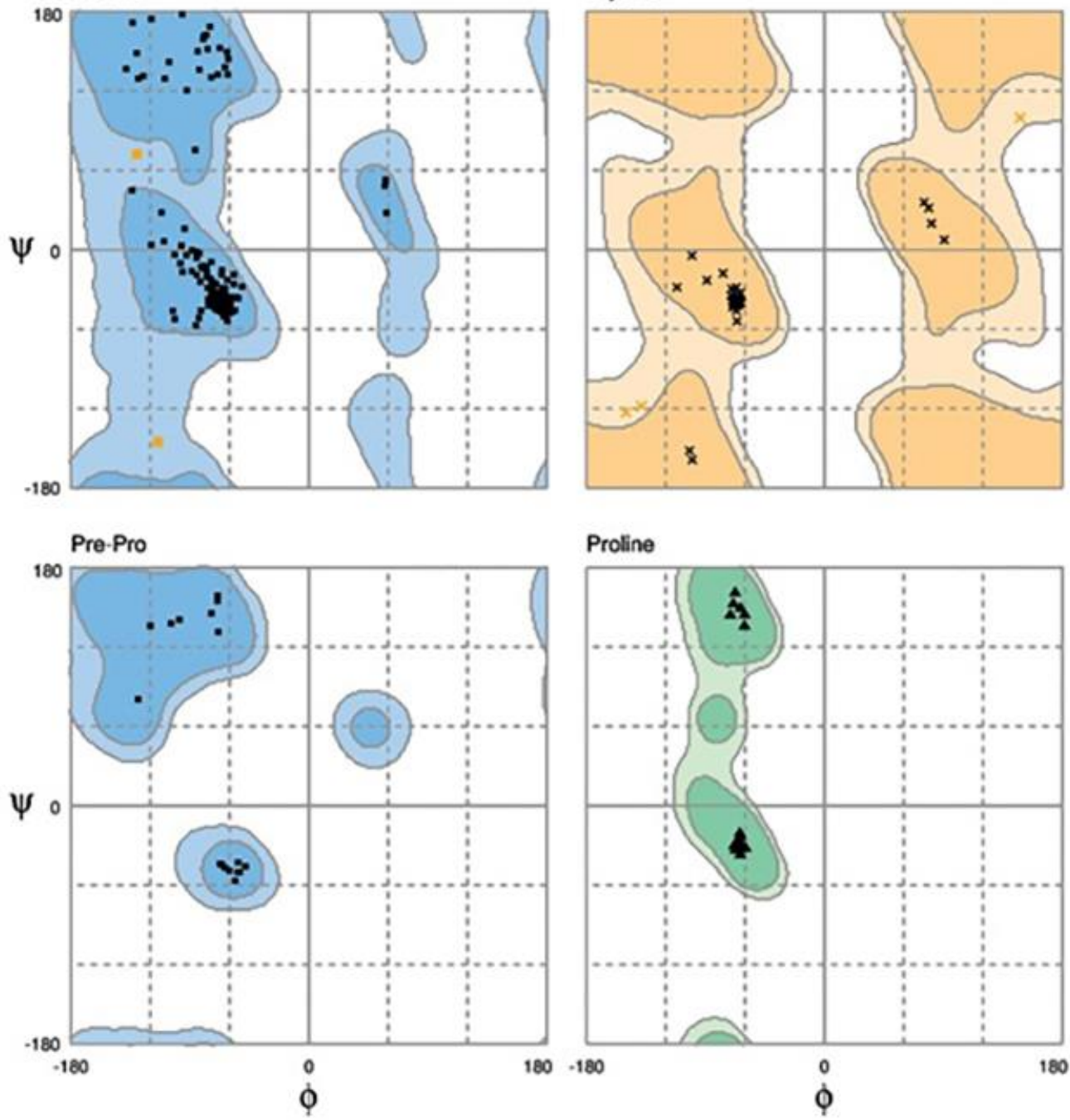

\section{Proline}

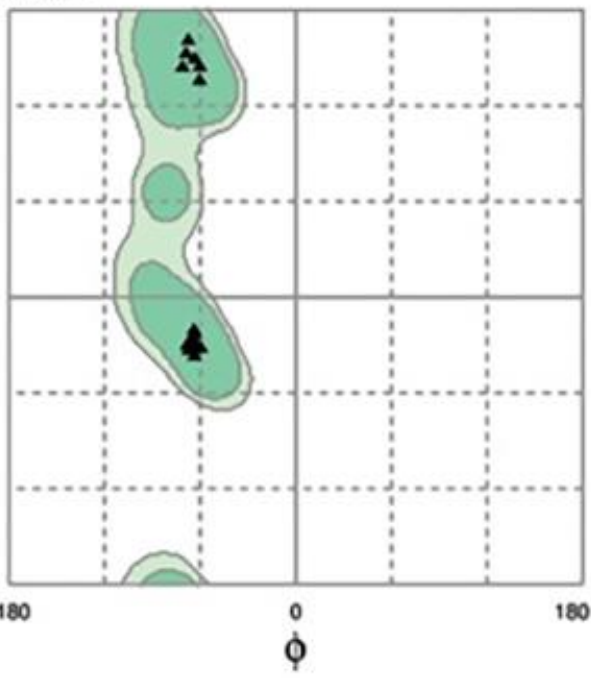

General Favoured

General Allowed

Glycine Favoured

Glycine Allowed

Pre.Pro Favoured

Pre-Pro Allowed

Proline Favoured

Proline Allowed

Number of residues in favoured region ( $-98.0 \%$ expected) : 395 (98.8\%)

Number of residues in allowed region $(-2.0 \%$ expected $) \quad: 5(1.2 \%)$

Number of residues in outlier region

: $0(0.0 \%)$ 
Fig. 3

A

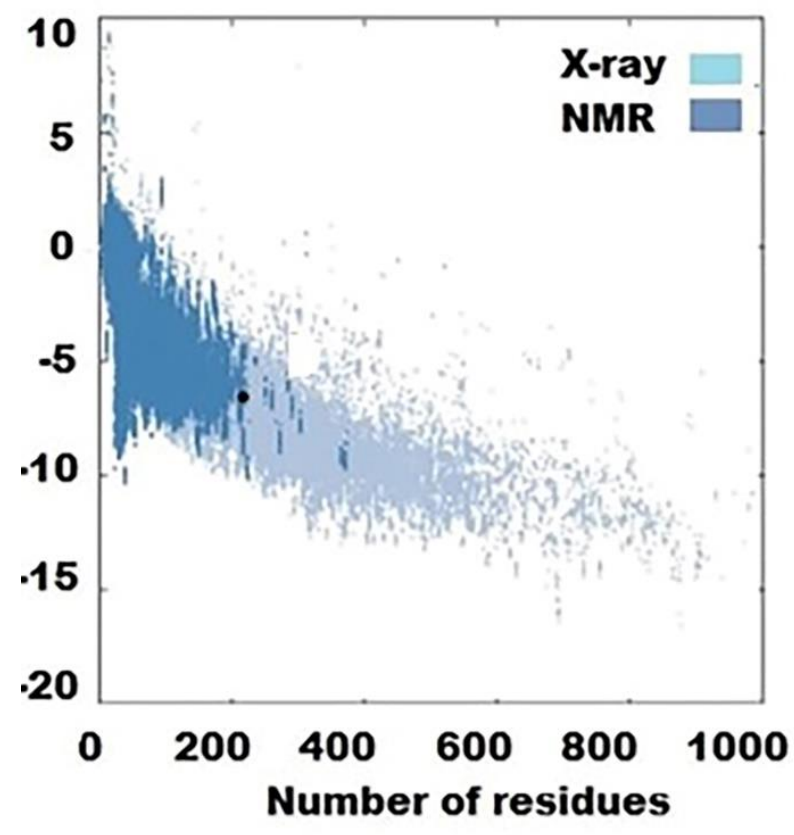

B

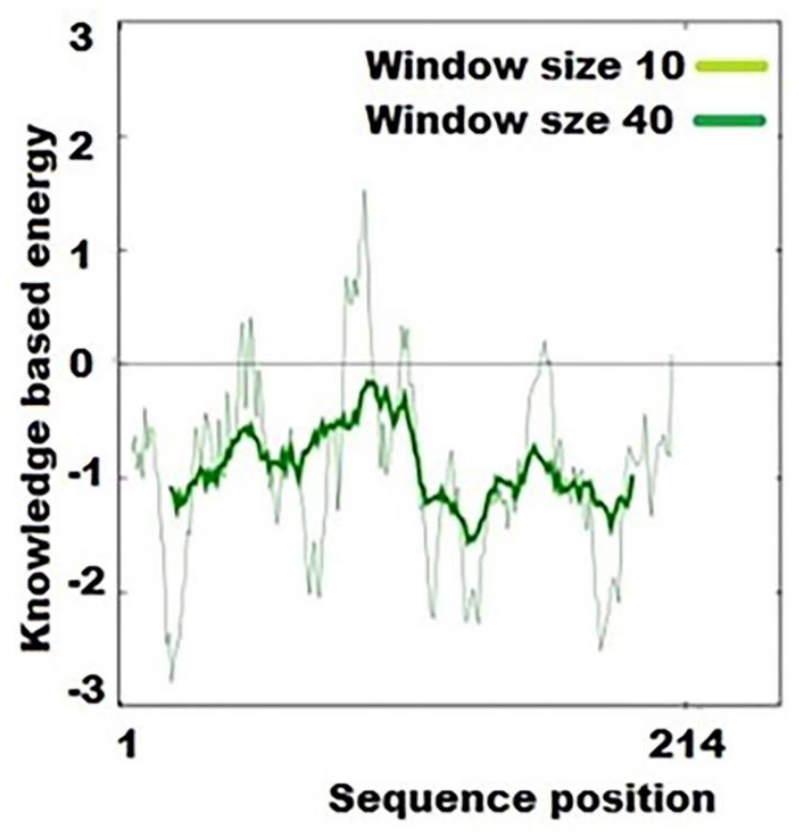


Fig. 4
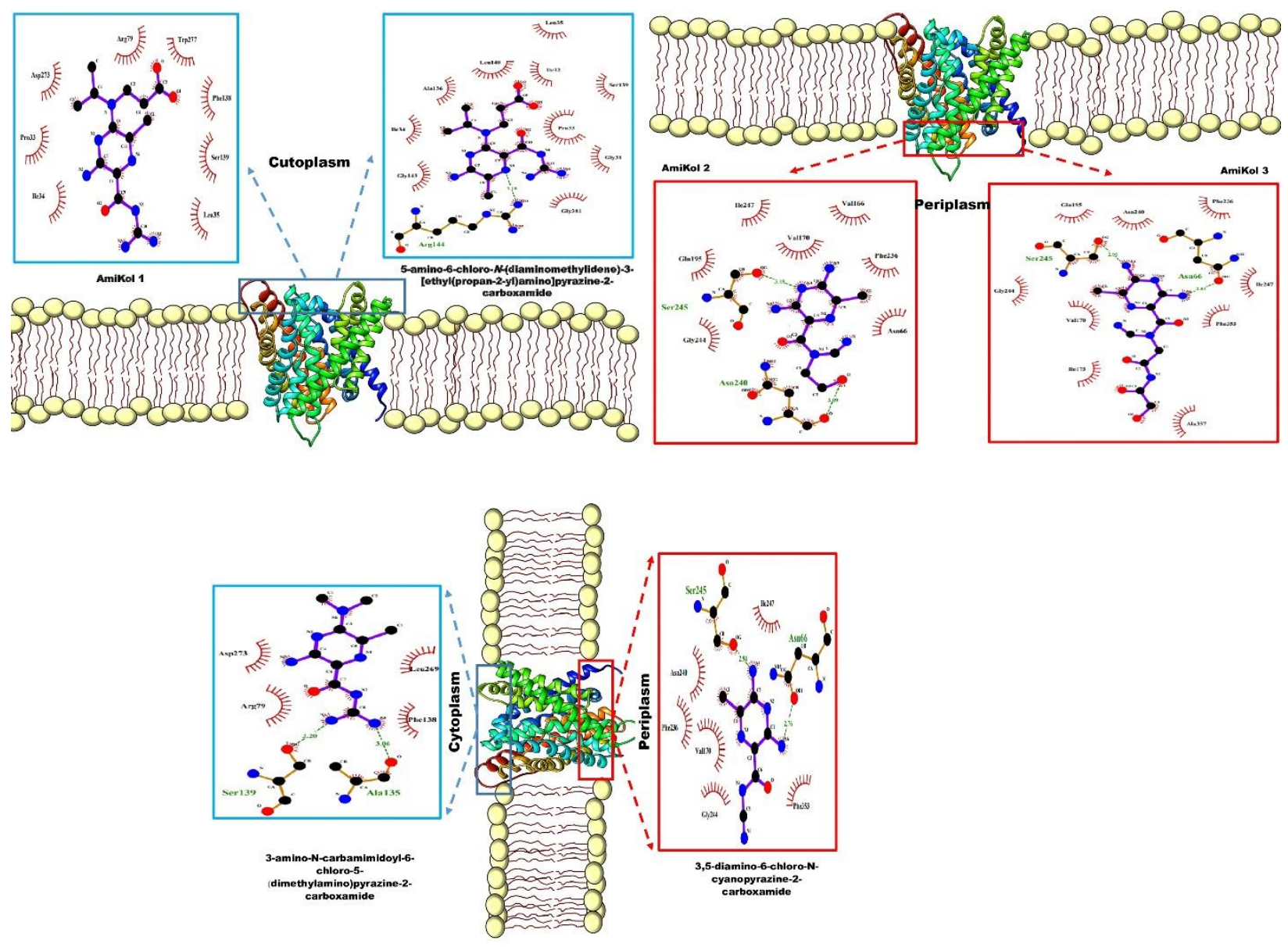


\section{Fig. 5}

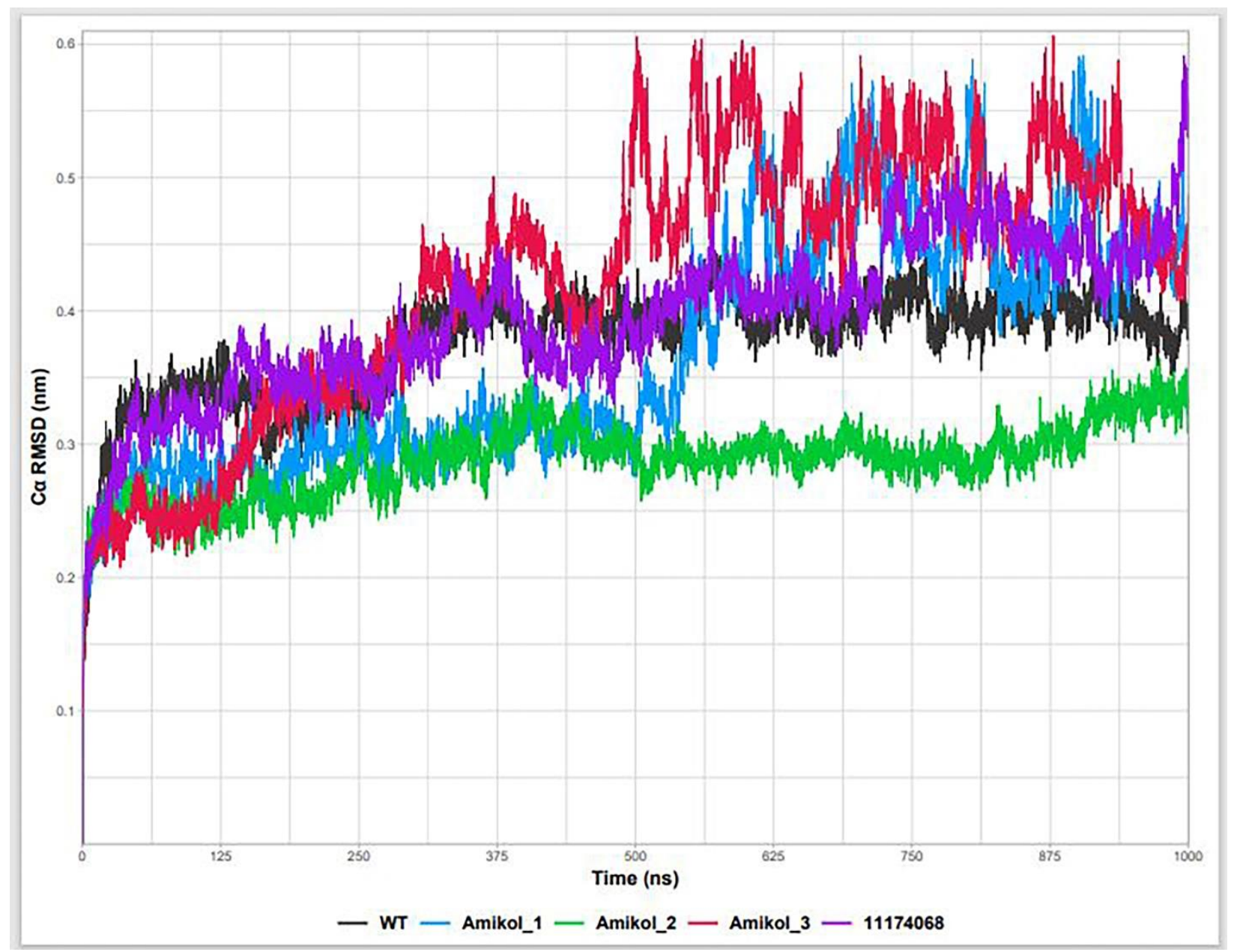


Fig. 6

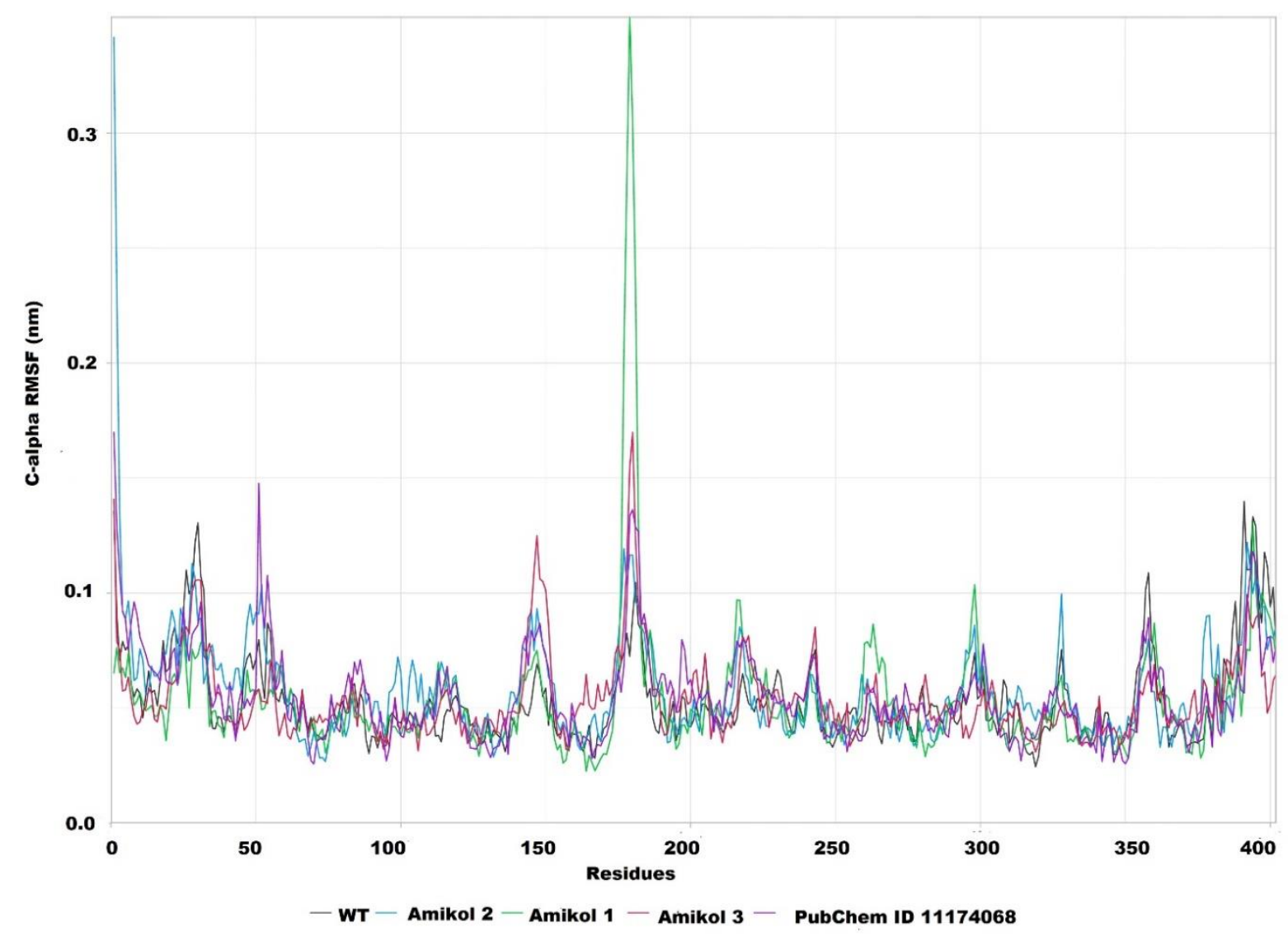


Table 1. Absorption, distribution, metabolism, excretion and toxicity analysis of the selected and designed drugs

\begin{tabular}{|c|c|c|c|c|c|c|}
\hline Properties & $\begin{array}{l}\text { 3,5-diamino- } \\
\text { 6-chloro-N- } \\
\text { cyanopyrazi } \\
\text { ne-2- } \\
\text { carboxamid } \\
\text { e } \\
\text { PubChem } \\
\text { CID: } \\
123478999\end{array}$ & $\begin{array}{l}\text { 5-amino-6- } \\
\text { chloro- } N- \\
\text { (diaminom } \\
\text { ethylidene)- } \\
\text { 3- } \\
\text { [ethyl(prop } \\
\text { an-2- } \\
\text { yl)amino]p } \\
\text { yrazine-2- } \\
\text { carboxami } \\
\text { de } \\
\text { PubChem } \\
\text { CID: } \\
\text { 11174068 }\end{array}$ & $\begin{array}{l}\text { 3-amino- } N \text { - } \\
\text { carbamimi } \\
\text { doyl-6- } \\
\text { chloro-5- } \\
\text { (dimethyla } \\
\text { mino)pyraz } \\
\text { ine-2- } \\
\text { carboxami } \\
\text { de } \\
\text { PubChem } \\
\text { CID: } \\
137630036\end{array}$ & $\begin{array}{l}\text { AmiKol 1 } \\
\text { (Modified } \\
\text { from } \\
\text { PubChem } \\
\text { CID: } \\
\text { 13763003 } \\
6\end{array}$ & $\begin{array}{l}\text { AmiKol } \\
2 \\
\text { (Modifie } \\
\text { d from } \\
\text { PubChe } \\
\text { m CID: } \\
\text { 1234789 } \\
\text { 99) }\end{array}$ & $\begin{array}{l}\text { AmiKol } \\
3 \\
\text { (Modified } \\
\text { from } \\
\text { PubChem } \\
\text { CID: } \\
\text { 123478999) }\end{array}$ \\
\hline $\begin{array}{l}\text { Caco2 } \\
\text { permeability } \\
\text { (log Papp in } 10- \\
6 \mathrm{~cm} / \mathrm{s})\end{array}$ & -0.213 & -0.076 & -0.23 & -0.153 & 0.381 & 0.511 \\
\hline $\begin{array}{l}\begin{array}{l}\text { Intestinal } \\
\text { absorption } \\
\text { (human) } \\
\text { Absorbed }\end{array} \\
\end{array}$ & 60.32 & 58 & 53 & 18 & 52 & 40 \\
\hline $\begin{array}{l}\text { Skin } \\
\text { Permeability } \\
(\log K p) \\
\end{array}$ & -2.819 & -2.735 & -2.735 & -2.735 & -2.771 & -2.738 \\
\hline $\begin{array}{l}\text { P-glycoprotein } \\
\text { substrate }\end{array}$ & No & Yes & Yes & yes & No & No \\
\hline $\begin{array}{l}\text { P-glycoprotein I } \\
\text { inhibitor }\end{array}$ & No & No & No & No & No & No \\
\hline $\begin{array}{l}\text { P-glycoprotein } \\
\text { II inhibitor }\end{array}$ & No & No & No & No & No & No \\
\hline $\begin{array}{l}\text { OATP1B1 } \\
\text { inhibitor }\end{array}$ & Positive & Positive & Negative & Positive & Positive & Positive \\
\hline $\begin{array}{l}\text { OATP2B1 } \\
\text { inhibitor }\end{array}$ & Negative & Negative & Negative & Negative & Negative & Negative \\
\hline $\begin{array}{l}\text { OATP1B3 } \\
\text { inhibitor }\end{array}$ & Positive & Positive & Negative & Negative & Positive & Negative \\
\hline
\end{tabular}




\begin{tabular}{|c|c|c|c|c|c|c|}
\hline $\begin{array}{l}\text { MATE1 } \\
\text { inhibitor }\end{array}$ & Negative & Positive & Negative & Negative & Negative & Negative \\
\hline BSEP inhibitor & Negative & Negative & Negative & Negative & Negative & Negative \\
\hline $\begin{array}{l}\text { Volume of } \\
\text { Distribution } \\
\text { (human) } \\
\mathrm{L} / \mathrm{kg}))\end{array}$ & -0.152 & 0.216 & -0.163 & -0.588 & -0.384 & -0.527 \\
\hline $\begin{array}{l}\text { Fraction } \\
\text { unbound } \\
\text { (human) }(\mathrm{Fu})\end{array}$ & 0.702 & 0.679 & 0.737 & 0.687 & 0.693 & 0.693 \\
\hline $\begin{array}{l}\text { BBB } \\
\text { permeability } \\
(\log B B)\end{array}$ & -0.923 & -0.955 & -1.181 & -0.827 & -1.19 & -1.14 \\
\hline $\begin{array}{l}\text { CNS } \\
\text { permeability } \\
(\log P S)\end{array}$ & -3.233 & -3.642 & -3.701 & -3.813 & -3.76 & -3.99 \\
\hline $\begin{array}{l}\text { Total Clearance } \\
(\log \mathrm{ml} / \mathrm{min} / \mathrm{kg})\end{array}$ & -0.139 & 0.219 & 1.016 & 0.065 & 0.245 & -1.131 \\
\hline $\begin{array}{l}\text { Renal OCT2 } \\
\text { substrate }\end{array}$ & No & Yes & No & No & No & No \\
\hline OCT2 inhibitor & Negative & Negative & Negative & Negative & Negative & Negative \\
\hline AMES toxicity & No & No & No & No & No & No \\
\hline $\begin{array}{lr}\text { Max. } & \text { tolerated } \\
\text { dose } & \text { (human) } \\
(\log \mathrm{mg} / \mathrm{kg} / \text { day })\end{array}$ & 0.643 & 1.178 & 0.77 & 0.953 & 0.673 & 0.861 \\
\hline $\begin{array}{ll}\text { hERG } & \text { I } \\
\text { inhibitor } & \end{array}$ & No & No & No & No & No & No \\
\hline $\begin{array}{ll}\text { hERG } & \text { II } \\
\text { inhibitor } & \end{array}$ & No & No & No & No & No & No \\
\hline Hepatotoxicity & No & No & Yes & No & No & $\begin{array}{l}\text { Yes } \\
\text { (lower than } \\
\text { parent } \\
\text { compound }\end{array}$ \\
\hline
\end{tabular}




\begin{tabular}{|l|l|l|l|l|l|l|}
\hline & & & & & & $\begin{array}{l}\text { according to } \\
\text { Protox) }\end{array}$ \\
\hline $\begin{array}{l}\text { Protox Mutagen } \\
\text { Probability }\end{array}$ & Active & Inactive & Active & Inactive & Inactive & Inactive \\
\hline $\begin{array}{l}\text { Osiris } \\
\text { Mutagenicity }\end{array}$ & No & No & No & No & No & Inactive \\
\hline $\begin{array}{l}\text { Protox } \\
\text { Immuno- } \\
\text { toxicity }\end{array}$ & Inactive & Inactive & Inactive & Inactive & Inactive & Inactive \\
\hline $\begin{array}{l}\text { Protox } \\
\text { Cytotoxicity }\end{array}$ & Inactive & Inactive & Inactive & Inactive & Inactive & Inactive \\
\hline $\begin{array}{l}\text { Protox } \\
\text { carcinogenicity }\end{array}$ & Inactive & Inactive & Inactive & Inactive & Inactive & Inactive \\
\hline $\begin{array}{l}\text { Osiris } \\
\text { Tumorigenic }\end{array}$ & No & No & No & No & No & No \\
\hline $\begin{array}{l}\text { Osiris irritant } \\
\text { No }\end{array}$ & Yes & No & No & Yes & Yes \\
\hline $\begin{array}{l}\text { Osiris } \\
\text { effect }\end{array}$ & No & No & No & No & No & No \\
\hline
\end{tabular}


Table 2. Interaction of drugs and Nhap2 with participated amino acid residues

\begin{tabular}{|c|c|c|c|c|}
\hline Compound Name & $\begin{array}{l}\text { Highest } \\
\text { Binding } \\
\text { Affinity } \\
\text { by } \\
\text { AutoDock } \\
\text { Vina } \\
\text { (kcal/mol) }\end{array}$ & $\begin{array}{l}\text { Highest } \\
\text { Binding } \\
\text { by } \\
\text { Achillies } \\
\text { (kcal/mol) }\end{array}$ & $\begin{array}{l}\text { Drug Binding } \\
\text { Residues (H- bond } \\
\text { forming residues } \\
\text { are italicized) }\end{array}$ & $\begin{array}{l}\text { Participated } \\
\text { Trans } \\
\text { Membrane } \\
\text { Segments (TMS) } \\
\text { and loops }\end{array}$ \\
\hline $\begin{array}{l}\text { 3,5-diamino-6-chloro-N- } \\
\text { cyanopyrazine-2- } \\
\text { carboxamide } \\
(123478999)\end{array}$ & -5 & -6 & $\begin{array}{l}\text { Asn } 66 \text {, Val } 170, \\
\text { Phe } 236 \text {, Asn } 240, \\
\text { Ser } 245 \text {, Ile } 247 \text {, } \\
\text { Gly } 244 \text {, Phe } 353\end{array}$ & $\begin{array}{l}\text { Periplasmic side } \\
\text { of TMSs V, VI, } \\
\text { VII and XII, Loop } \\
\text { between TMSs } \\
\text { VIII-IX }\end{array}$ \\
\hline $\begin{array}{l}\text { AmiKol 2 } \\
\text { 123478999) }\end{array}$ & -7.3 & -5.5 & $\begin{array}{l}\text { Asn 66, Val 166, } \\
\text { Val 170, Gln 195, } \\
\text { Phe 236, Asn 240, } \\
\text { Gly 244, Ser 245, } \\
\text { Ile 247 }\end{array}$ & $\begin{array}{l}\text { Periplasmic side } \\
\text { of TMSs III, VI } \\
\text { and VII, loop } \\
\text { between TMSs } \\
\text { VIII-IX. }\end{array}$ \\
\hline $\begin{array}{l}\text { AmiKol } 3 \text { (Modified } \\
\text { 123478999) }\end{array}$ & -6.1 & -6.6 & $\begin{array}{l}\text { Asn 66, Val 170, } \\
\text { Ile 173, Gln 195, } \\
\text { Phe 236, Asn 240, } \\
\text { Gly 244, Ser 245, } \\
\text { Ile 247, Phe 353, } \\
\text { Ala 357 }\end{array}$ & $\begin{array}{l}\text { Periplasmic side } \\
\text { of TMSs III, VI } \\
\text { and VII, loop } \\
\text { between TMSs } \\
\text { VIII-IX and XII- } \\
\text { XIII. }\end{array}$ \\
\hline $\begin{array}{l}\text { 3-amino- } N \text { - } \\
\text { carbamimidoyl-6-chloro- } \\
5 \text { - } \\
\text { (dimethylamino)pyrazine- } \\
\text { 2-carboxamide } \\
(137630036)\end{array}$ & -6.2 & -5.9 & $\begin{array}{l}\text { Arg } 79, \text { Ala } 135, \\
\text { Phe 138, Ser 139, } \\
\text { Leu 269, Asp } 273\end{array}$ & $\begin{array}{l}\text { Cytoplasmic side } \\
\text { of TMSs IV, V } \\
\text { and X }\end{array}$ \\
\hline $\begin{array}{l}\text { AmiKol } 1 \text { (Modified } \\
\text { from 137630036) }\end{array}$ & -5.7 & -6 & $\begin{array}{l}\text { Pro 33, Ile 34, Leu } \\
\text { 35, Arg 79, Phe } \\
\text { 138, Ser 139, Asp } \\
\text { 273, Trp 277 }\end{array}$ & $\begin{array}{l}\text { Cytoplasmic side } \\
\text { of TMSs IV, V } \\
\text { and X }\end{array}$ \\
\hline
\end{tabular}




\begin{tabular}{|c|c|c|c|c|}
\hline $\begin{array}{l}\text { 5-amino-6-chloro- } N \text { - } \\
\text { (diaminomethylidene)-3- } \\
\text { [ethyl(propan-2- } \\
\text { yl)amino]pyrazine-2- } \\
\text { carboxamide } \\
(11174068)\end{array}$ & -5.7 & -5.3 & 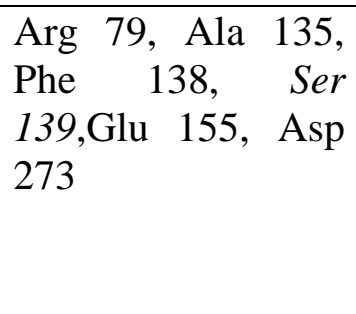 & $\begin{array}{l}\text { Cytoplasmic side } \\
\text { of TMSs III, V, } \\
\text { VI and X. }\end{array}$ \\
\hline
\end{tabular}

Table 3: Physicochemical properties of the finally selected drug

\begin{tabular}{|c|c|c|c|c|}
\hline Compounds Name: & $\begin{array}{c}\text { AmiKol } 2 \\
\text { (Modified } \\
\text { 123478999) }\end{array}$ & $\begin{array}{c}\text { AmiKol } 3 \\
\text { (Modified } \\
\text { 123478999) }\end{array}$ & $\begin{array}{c}\text { AmiKol 1 } \\
\text { (Modified } \\
\text { 137630036) }\end{array}$ & $\begin{array}{l}\text { 5-amino-6-chloro- } N \text { - } \\
\text { (diaminomethylidene)-3- } \\
\text { [ethyl(propan-2- } \\
\text { yl)amino]pyrazine-2- } \\
\text { carboxamide } \\
(11174068)\end{array}$ \\
\hline Formula & $\mathrm{C}_{8} \mathrm{H}_{9} \mathrm{C}_{1} \mathrm{~N}_{6} \mathrm{O}_{2}$ & $\mathrm{C}_{10} \mathrm{H}_{10} \mathrm{C}_{1} \mathrm{~N}_{7} \mathrm{O}_{4}$ & $\mathrm{C}_{12} \mathrm{H}_{18} \mathrm{C}_{1} \mathrm{~N}_{7} \mathrm{O}_{3}$ & $\mathrm{C}_{11} \mathrm{H}_{18} \mathrm{C}_{1} \mathrm{~N}_{7} \mathrm{O}$ \\
\hline $\begin{array}{l}\text { Molecular weight } \\
(\mathrm{g} / \mathrm{mol})\end{array}$ & 256.65 & 327.68 & 343.77 & 299.76 \\
\hline $\begin{array}{c}\text { Number of heavy } \\
\text { atoms }\end{array}$ & 17 & 22 & 23 & 20 \\
\hline $\begin{array}{c}\text { Number of aromatic } \\
\text { heavy atoms }\end{array}$ & 6 & 6 & 6 & 6 \\
\hline Fraction Csp3 & 0.25 & 0.20 & 0.42 & 0.45 \\
\hline $\begin{array}{c}\text { Number of rotatable } \\
\text { bonds }\end{array}$ & 4 & 7 & 8 & 5 \\
\hline $\begin{array}{c}\text { Number of } \\
\text { H-bond acceptors }\end{array}$ & 5 & 7 & 5 & 4 \\
\hline $\begin{array}{c}\text { Number of } \\
\text { H-bond donors }\end{array}$ & 3 & 4 & 4 & 3 \\
\hline Molar Refractivity & 59.47 & 72.28 & 84.67 & 79.37 \\
\hline $\begin{array}{l}\text { Topological Polar } \\
\text { Surface Area }\left(\AA^{2}\right)\end{array}$ & 142.15 & 188.32 & 175.88 & 136.51 \\
\hline
\end{tabular}


Table 4. MolProbity results of refined Vc-NhaP2 protein structure as predicted by SWISSMODEL

\begin{tabular}{|c|c|}
\hline MolProbity Score & 0.71 \\
\hline Clash Score & 0 \\
\hline $\begin{array}{l}\text { Ramachandran } \\
\text { Favoured }\end{array}$ & $98.75 \%$ \\
\hline Ramachandran Outliers & $0.0 \%$ \\
\hline Rotamer Outliers & $\begin{array}{l}\text { 1.90\% (A112 MET, A69 LEU, A168 LEU, A106 LEU, A16 } \\
\text { LEU, A146 LEU) }\end{array}$ \\
\hline C-Beta Deviations & $\begin{array}{l}10 \text { (A112 MET, A218 GLN, A346 VAL, A145 SER, A90 } \\
\text { TRP, A283 MET, A380 GLN, A339 TRP, A55 PHE, A85 PHE) }\end{array}$ \\
\hline Bad Bonds & 0 \\
\hline
\end{tabular}




\section{Discussion}

The rising incidence of multidrug-resistant $V$. cholerae outbreaks is an emerging issue in developing countries [1,3]. A great deal of research has been done to investigate the role of resistance-inducing multidrug efflux antiporters whereas cation-proton antiporters have not been considered possible targets for drug targeting [55-56]. Since cation-proton antiporters play a major role in the survival of the bacteria, blocking their activity with suitable drugs could be a prospective therapy [16].

As we reported, the membrane of $V$. cholerae contains a trio of cation-proton antiporters of a specific type, NhaP, that are responsible for the transport of both $\mathrm{K}^{+}$and $\mathrm{Na}^{+}[12-18]$. They are encoded by three paralogous structural genes, Vc-nhaP1, 2 and 3. Our phenotypical analysis of deletion mutants suggested that these antiporters play an essential role in bacterial physiology [12-18]. We hypothesized that they comprise a novel mechanism of the Acid Tolerance Response (ATR). Preliminary ATR tests conducted with the wild-type parental strain V. cholerae O395N1 and its triple deletion mutant $\mathrm{Vc} \Delta \mathrm{NhaP} 123$, showed that the triple mutant died at a much higher rate than the isogenic wild type strain upon being challenged by $\mathrm{HCl}(\mathrm{pH} 3.5)$, [13]. Considering the possible physiological role of Vc-NhaP isoforms in the ATR of $V$. cholerae, we hypothesized that the inhibition of $\mathrm{Vc}-\mathrm{NhaP}$ paralogues might inhibit the infectious process caused by this pathogen when it crosses the gastric acid barrier. Since Vc-NhaP2 could be a potential target for future drug development targeting these ion exchangers, inhibition of this protein alone might impair the overall infectious process caused by $V$. cholerae as it passes though the gastric acid barrier to initiate the infection $[13,16]$.

The NhaP-type antiporters are phylogenetically diverse and present in both eukaryotes and prokaryotes [12]. They also play a crucial role in enhancing the survival of different blood-borne 
pathogenic bacteria in human blood. For example, it was reported that survival of Yersinia pestis in blood is related to the presence of NhaA and NhaB sodium-proton antiporters. Deletion of these $\mathrm{Na}^{+} / \mathrm{H}^{+}$antiporters decreased its survival in blood [57]. Developing inhibitors against the Vc-NhaP2 antiporter might also be broadly applicable to the antiporters present in the genomes of pathogenic microorganisms [19].

For this study we selected Amiloride, a potent inhibitor of the human $\mathrm{Na}^{+} / \mathrm{H}^{+}$exchanger (NHE-1), as a lead compound to target Vc-NhaP2. After extensive exploration of ADMET and QSAR properties, we used in silico methods to determine the pharmacological consequences of AMLRD and its analogues (Supplementary file 1). Among them, six AMLRD analogs with modest pharmacokinetic features and the lowest toxicities were obtained for molecular docking simulations against Vc-NhaP2. The selected compounds demonstrate average binding affinity scores around $-6.0 \mathrm{kcal} / \mathrm{mol}$. Docking studies clearly indicate two potential binding sites; either at the cytoplasmic side or at the periplasmic side of the protein (Table 2). Moreover, amino acid residues located in TMSs IV, V, VI and the loop between VIII-XII are involved in drug binding. Importantly, TMS V, VI and XII are crucial for the functioning of the Vc-NhaP2 antiporter, as amino acid residues present on these TMSs are directly involved in cation binding $[16,18]$.

Toxicity is a major issue during drug development. Around $33 \%$ of drug candidates cannot pass all the clinical trials due to their toxicity and result in significant economic costs [58]. AMLRD and its analogs contain chemical properties that can lead to hepatoxicity and mutagenicity (Supplementary file 1) [59]. To overcome these problems, the results of pkCSM, admetSAR 2.0, OSIRIS property explorer and ProTox-II were used to evaluate drug toxicities. Especially, data generated by ProTox-II were evaluated meticulously since this virtual lab was established to decrease animal model experiments by integrating robust prediction models on 
drug toxicity [32]. These analyses indicated that some of the selected compounds have are potentially toxic thus rational drug design was conducted to lessen the toxicity of particular drug candidates (Table 1). However, some designed molecules such as AmiKol 2 and 3 still contains irritant characteristics though Amikol 3 has reduced hepatotoxic properties. To ensure proper safety, these drugs require in vitro and in vivo validations. These drugs with lower toxicity also demonstrated nearly the same binding scores as their parent compound showed against the VcNhaP2. Lastly, the final drug candidates have minimum toxicity and maintain Lipinski's rule of five (Table 3) [60].

The four optimal NhaP2-drug complexes were elected for MD simulation where these complexes were embedded in a lipid bilayer membrane mimicking the native membrane of $V$. cholerae [49]. MD simulations for apo-Vc-NhaP2 revealed that the positions of the amino acid residues forming the putative cation binding pocket present in TMSs VI did not show any significant fluctuations compared to the residues present in other TMSs V and XII (Figure 6). We previously suggested that the conformational changes occurring in TMSs V and XII in VcNhaP2 alternatively opens the rigid ion binding pocket in TMS VI either to the cytoplasm or to the periplasmic side [16]. In the present study we have hypothesized that binding of our drug candidates would possibly affect the flexibility or the rigidity of crucial TMSs of Vc-NhaP2 destabilizing the protein and hence altering its function. Our findings clearly suggest that drugbound structures have higher flexibility in the amino acid residues present in the TMS VI involved in ion binding (Figure 5). This observation indicates that the binding of drugs could plausibly affect the flexibility of the $\mathrm{Vc}-\mathrm{NhaP} 2$ which is essential for the functioning of the antiporter. In addition, upon drug binding the global structure of Vc-NhaP2 deviated from the unbound structure (Figure 5). 
In future these candidate drugs should be compared with commonly-used antibiotics for cholera such as Doxycycline, Tetracycline or Azithromycin. This comparison will help to assess their anti-cholera activity in in vitro and in vivo models for proper establishment.

\section{Materials and Methods}

\subsection{Selection of a lead compound}

Since Vc-NhaP2 participates in $\mathrm{K}^{+}$or $\mathrm{Na}^{+} / \mathrm{H}^{+}$exchange, selection of a $\mathrm{Na}^{+}$antiporter inhibitor is a rational approach to targeting of $V$. cholerae. To find a potential $\mathrm{Na}^{+} / \mathrm{H}^{+}$inhibitor, we searched the World Health Organization (WHO) Model List of Essential Medicines (2019) [25]. This list contains the drugs that are considered as the most efficient and safe for humans. From the list, we chose Amiloride (AMLRD), because this diuretic can block sodium-hydrogen exchange in humans [26]. Additionally, AMLRD and its analogues have shown broad spectrum in vitro antibacterial activity [22-24]. AMLRD is widely used to inhibit the mammalian $\mathrm{Na}^{+} / \mathrm{H}^{+}$ exchanger isoform 1 (NHE1) [21] in cardiac diseases. Both NHE1 and Vc-NhaP2 belong to the same cation/proton antiport superfamily-1 (CPA-1) and have similarities at the protein structural level [16]. AMRLD and its different analogs have also been used as anti-cancer drugs [27].

\subsection{Selection and preparation of amiloride analogues as ligands}

The Canonical SMILES of forty-five AMLRD analogs were collected from the PubChem database. Cheminformatics analysis was carried out with the use of the Molinspiration suite (https://www.molinspiration.com/). Absorption, Distribution, Metabolism and Toxicity (ADMET) properties were calculated by pkCSM, admetSAR 2.0, SwissADME, and ProToxII [28-31], respectively. Quantitative Structure-Activity Relationships (QSAR) were computed 
with the OSIRIS Property Explorer (https://www.organic-chemistry.org/prog/peo/). The Canonical Smiles of the selected AMLRD analogs showing lower toxicity profile (NonMutagenic, non-hepatotoxic, non-immunogenic and non-cytotoxic) (Supplementary Excel File) were then converted into Protein Data Bank (PDB) files. To do so, the Canonical SMILES of the selected ligands were uploaded in the Online SMILES Translator and Structure File Generator (https://cactus.nci.nih.gov/translate/).

\subsection{Preparation of the structural model for Vc-NhaP2 antiporter}

A structural model of $\mathrm{Vc}-\mathrm{NhaP} 2$ was generated using the catalytically-active transmembrane segments consisting of 581 amino acids; the full-length protein contains an additional 391 amino acids that comprise a cytoplasmic domain [18, 32]. It is presumed that the cytoplasmic domain of $\mathrm{Vc}-\mathrm{NhaP} 2$ does not participate in direct cation binding as its deletion does not have any significant impact on the function of Vc-NhaP2 [32]. The structural model of Vc-NhaP2 was generated by Rosetta [33] software using the Robetta server [34] (http://robetta.bakerlab.org) and was visualized with PyMol [35]. The Rosetta-generated structure has a Template Model-score of 0.865 with respect to PDB ID: $4 \mathrm{CZB}$ the $\mathrm{Na}^{+} / \mathrm{H}^{+}$ antiporter Pa-NhaP from the archeon Pyrococcus abyssi [36]. The Template Model-score is a measure of the similarity between two protein structures with different tertiary structures. The Vc-NhaP2 structure generated using Rosetta software [33] on the Robetta server [34] was further refined using locPREFMD [38] (frig.bch.msu.edu). locPREFMD refines protein structures via molecular-dynamics simulations [38]. Ramachandran plots for the structural model of Vc-NhaP2 were generated by Rampage (http://www cryst.bioc.cam.ac.uk/rampage) [37]. The quality of the generated structure was checked using SWISS-MODEL (swissmodel.expasy.org) [39] and ProSA-web [64]. 


\subsection{Molecular docking between Vc-NhaP2 and drug candidates}

To discover the interactions between $\mathrm{Vc}-\mathrm{NhaP} 2$ and the six selected drug candidates, molecular docking was executed by AutoDock Vina (ADV) [41]. Here, Vc-NhaP2 was selected as antiporter and the nominated AMLRD analogues were designated as ligands. Since, there is no prior knowledge about the drug binding site in $V$. cholerae NhaP2 a blind docking approach was employed [42]. The number of torsion angles was kept at zero in the ligands and the polar hydrogen bonds were added in the protein. ADV is a renowned software for molecular docking that gave probable binding sites of the drugs with a binding score [42]. The binding site with the best binding score was taken for further analysis. In addition, the Achilles Blind Docking Server (https://bio-hpc.ucam.edu/achilles/) was implemented for additional validation. This web-based server has been used in different academic and industrial purposes for blind molecular docking. The best binding scores for each protein-drug complex derived from the Achilles Blind Docking server were also collected. ADV deduced interactions between the drugs and Vc-NhaP2 were visualized by PyMol [35], UCSF Chimera [43] and LigPlot ${ }^{+}$[44].

\subsection{Rational drug design}

Based on the best potential binding score of the protein-ligand complexes (Table 2) and toxicity profiles (Table 1), two drugs (3,5-diamino-6-chloro-N-cyanopyrazine-2-carboxamide, PubChem CID: 123478999 and 3-amino- $N$-carbamimidoyl-6-chloro-5(dimethylamino)pyrazine2-carboxamide, PubChem CID: 137630036) were selected for modification in order to reduce their toxicity and mutagenicity. To do so, Structure Activity Relationship (SAR) of AMLRD were explored by reviewing the literature [45-46]. Then, SAR helped to identify the side-chains or functional groups to be manipulated. Secondly, drug-antiporter complexes were examined thoroughly after molecular docking. This facilitated the detection of the atoms that were critical 
during ligand-protein interactions. Following this, the compounds were modified via Molinspiration (https://www.molinspiration.com/) (Figure 1).

\subsection{Energy minimization of the modified drugs}

Computationally-designed drugs require energy minimization to improve physical realism, side-chain accuracy and stereochemistry [47-48]. To perform energy minimization, the PDB files of the modified drugs were input into the YASARA (Yet Another Scientific Artificial Reality Application) Energy Minimization Server. YASARA performed knowledge-based forcefield energy minimization [48]. The energy-minimized structures were then docked to the refined protein structure.

\subsection{Molecular Dynamics (MD) Simulations}

MD simulations were carried out to compare the stability and dynamics of VcNhaP2 and drug-Vc-NhaP2 complexes. The ligand-bound protein structures generated by ADV [41] were embedded in a lipid bilayer membrane composed of mixed 1-palmitoyl

2-oleoylphosphatidylethanolamine (POPE) (80\%)/1-palmitoyl-2-oleoylphosphatidylglycerol

(POPG) (20\%). The lipid bilayer membrane composition was generated based on the original composition of $V$. cholerae classical ogawa strain [49]. The water, lipid and protein components were extensively energy minimized using the Charmm-Gui Bilayer Builder [50-51] and Gromacs 2019.2 [52]. The total system consisted of about 120,000 atoms in an orthorhombic simulation cell with a free $\mathrm{KCl}$ concentration of $250 \mathrm{mM}$. Equilibrium $\mathrm{MD}$ simulations were performed after energy minimization and $1 \mu$ s of equilibration with position restraints. The total length of the simulation was 1 microsecond. All simulations were carried out under periodic boundary 
conditions at constant temperature $(\mathrm{T}=310 \mathrm{~K})$ and pressure $(\mathrm{P}=1 \mathrm{bar})$. Then the Root Mean Square Deviations (RMSD) and Root Mean Square Fluctuations (RMSF) of the C- $\alpha$ carbons of apo-Vc-NhaP2 and drug-bound -Vc-NhaP2 complexes were analysed using the g_rms and g_rmsf tools of Gromacs as described by Pathak et al. [53].

Supplementary Fig 1. Structure of Vc-NhaP2 antiporter. The TMSs are labelled. The extended chain region between TMSs V and XII is circled.

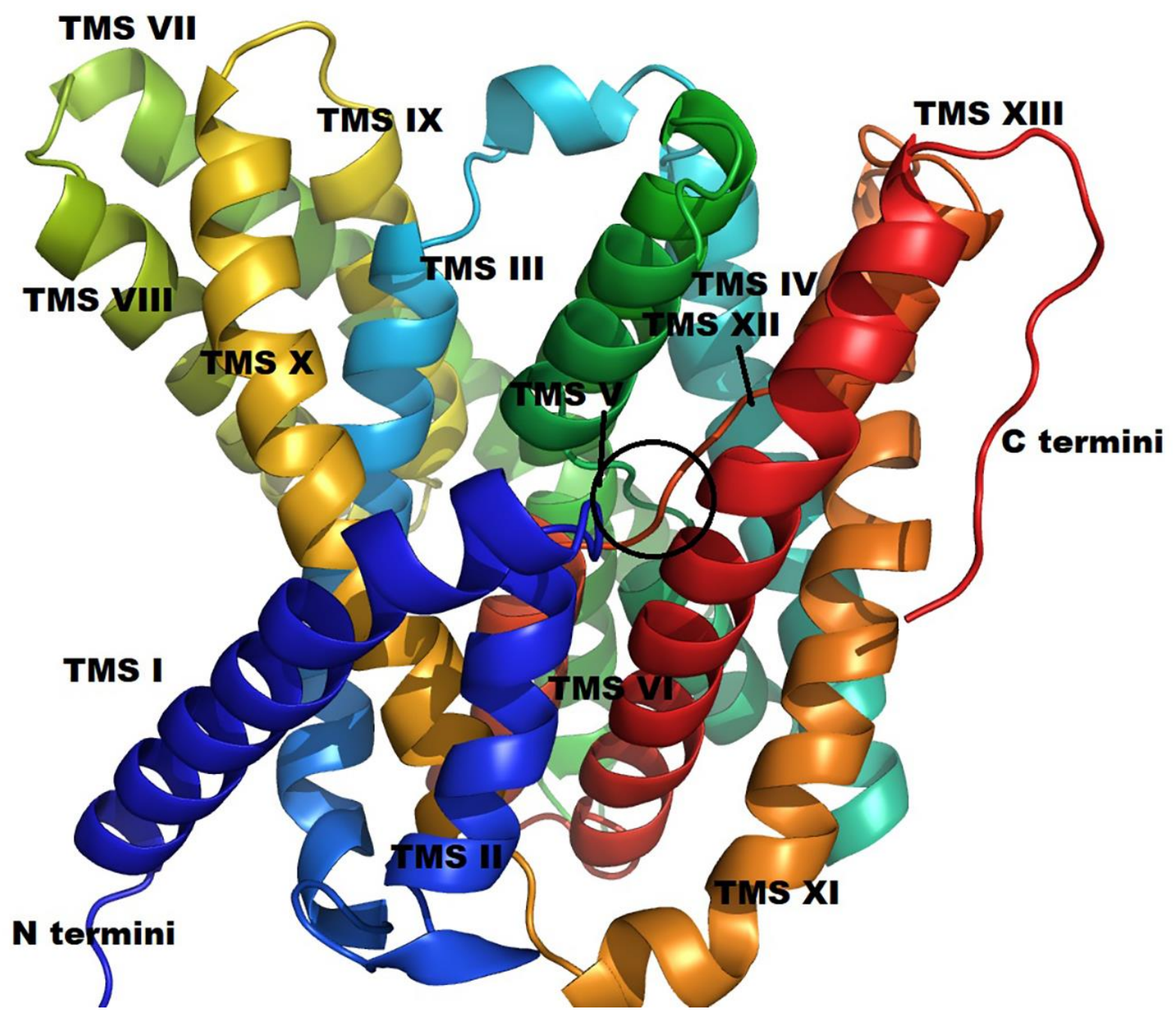




\section{Authors' contributions}

Conceptualization, Muntahi Mourin; Methodology, Muntahi Mourin, Joe O’Neil and Arritra Bhattacharjee ; Software, Alvan Wai, Arritra Bhattacharjee; Validation, Muntahi Mourin, Joe

O’Neil, J and George Hausner ; Investigation, Muntahi Mourin and Arritra Bhattacharjee; Writing - original draft preparation, Muntahi Mourin, Writing-review and editing, Muntahi Mourin, Arritra Bhattacharjee, Joe O’Neil and Pavel Dibrov; Visualization, Muntahi Mourin and Arritra Bhattacharjee; Supervision, Pavel Dibrov.

\section{Funding}

This research was funded by NSERC, the Natural Sciences and Engineering Research Council of Canada, grant number RGPIN-2019-05481 to M.M. and P.D.; RGPIN-2015-06658 to A.W. and G.H.; RGPIN-2016-06031 to J.O’N.

\section{Conflicts of Interest}

The authors declare no conflict of interest. The funders had no role in the design of the study; in the collection, analyses, or interpretation of data; in the writing of the manuscript, or in the decision to publish the results. 


\section{References}

1. Mandal, S., Mandal, M.D. and Pal, N.K. (2011). Cholera: a great global concern. Asian Pac. J. Trop. Med., 4(7): 573-580.

2. Faruque, S.M., Nair, G.B. and Mekalanos, J.J. (2004). Genetics of stress adaptation and virulence in toxigenic Vibrio cholerae. DNA Cell Biol. 23(11):723-41.

3. Das, B., Verma, J., Kumar, P., Ghosh, A. and Ramamurthy, T. (2020). Antibiotic resistance in Vibrio cholerae: Understanding the ecology of resistance genes and mechanisms. Vaccine. 38(1): A83-A92.

4. Asadgol, Z., Mohammadi, H., Kermani, M., Badirzadeh, A. and Gholami, M. (2019). The effect of climate change on cholera disease: The road ahead using artificial neural network. PloS one. 14(11), e0224813.

5. Gupta, S. S., Bharati, K., Sur, D., Khera, A., Ganguly, N. K., \& Nair, G. B. (2016). Why is the oral cholera vaccine not considered an option for prevention of cholera in India? Analysis of possible reasons. Indian J. Med. Res. 143(5), 545-551.

6. Geibel, J.P. (2005). Role of potassium in acid secretion. World J. Gastroenterol., 11(34): 5259-5265.

7. Heitzmann, D., Warth, R. (2007). No Potassium, No Acid: $\mathrm{K}^{+}$Channels and Gastric Acid Secretion. Physiol. 22: 335-341. doi:10.1152/physiol.00016.2007.

8. Merrell, D.S., Camilli, A. (1999). The cadA gene of Vibrio cholerae is induced during infection and plays a role in acid tolerance. Mol. Microbiol., 34:836-849.

9. Merrell, D.S., Camilli, A. (2000). Regulation of Vibrio cholerae genes required for acid tolerance by the member of the "ToxR-like" family of transcriptional regulators. J. Bacteriol.182: 5342-5350.

10. Merrell, D.S., Hava, D.L., Camilli, A. (2002). Identification of novel factors involved in colonization and acid tolerance of Vibrio cholerae. Mol. Microbiol. 43:1471-1491.

11. Kovacikova, G., Lin, W., Skorupski, K. (2010). The LysR-Type virulence activator AphB regulates the expression of genes in Vibrio cholerae in response to low $\mathrm{pH}$ and anaerobiosis. J. Bacteriol. 192 (6): 181-191.

12. Resch, C.T., Winogrodzki, J.L., Häse, C.C., Dibrov, P. (2011). Insights into the biochemistry of the ubiquitous NhaP family of cation/H+ antiporters. Biochem. Cell. Biol. 89:130-137. 
13. Mourin, M., Schubiger, C.B., Resch, C.T., Häse, C.C., Dibrov, P. (2017). Physiology of the Vc-NhaP paralogous group of cation-proton antiporters in Vibrio cholerae. Mol. Cell. Biochem. $428: 87-99$.

14. Resch, C. T., Winogrodzki, J. L., Patterson, C. T., Lind, E. J., Quinn, M. J., Dibrov, P., and Häse, C. C. (2010). The putative $\mathrm{Na}^{+} / \mathrm{H}^{+}$antiporter of Vibrio cholerae, Vc-NhaP2, mediates the specific $\mathrm{K}^{+} / \mathrm{H}^{+}$exchange in vivo. Biochem. 49: 2520-2528.

15. Quinn, M.J., Resch, C.T., Sun, J.; Lind, E.J., Dibrov, P., Häse, C.C. (2012). NhaP1 is a $\mathrm{K}^{+}\left(\mathrm{Na}^{+}\right) / \mathrm{H}^{+}$antiporter required for growth of Vibrio cholerae at low extracellular $\mathrm{pH}$. Microbiol. (UK). 158:1094-1105.

16. Mourin, M., Wai, A., O’Neil, J., Hausner, G., Dibrov, P. (2019). Physiological, structural and functional analysis of the paralogous cation-proton antiporters of NhaP type from Vibrio cholerae. Int. J. Mol. Sci. 20(10): 2572.

17. Schubiger, C.B., Mourin, M., Resch, C.T., Häse, C.C., Dibrov, P. (2017). Mutations of a single glycine in $\mathrm{Vc}-\mathrm{NhaP}$, a cation-proton antiporter in Vibrio cholerae, confer the ability to exchange $\mathrm{Li}^{+}$for $\mathrm{H}^{+}$. Mol. Cell. Biochem. 428 (1): 87-99.

18. Mourin, M., Wai, A., O’Neil, J., Schubiger, C. B., Häse, C. C., Hausner, G., Dibrov, P. (2018). A pathway leading to cation binding pocket determines the selectivity of NhaP2 antiporter in Vibrio cholerae. Biochem. Cell. Biol. 16: 1-8.

19. Dibrov, P., Dibrov, E., Pierce, C.T. (2017). $\mathrm{Na}^{+}-\mathrm{NQR} \quad\left(\mathrm{Na}^{+}\right.$-translocating NADH:ubiquinone oxidoreductase) as a novel target for antibiotics. FEMS Microbiol. Rev. 41(5):653-671.

20. Finkelstein, R.A. (1996). Cholera, Vibrio cholerae O1 and O139, and other pathogenic Vibrios. Medical Microbiology. 4th ed.; Galveston (TX): University of Texas, Medical Branch at Galveston, chapter 24.

21. Pedersen, S.F., King, S.A., Nygaard, E.B., Rigor, R.R. and Cala, P.M. (2007). NHE1 Inhibition by Amiloride- and Benzoylguanidine-type Compounds inhibitor binding loci deduced from chimeras of NHE1 homologues with differences in inhibitor sensitivity. J. Biol. Chem. 282(27):19716-27.

22. Giunta, S., Galeazzi, L., Turchetti, G., Sampaoli, G. and Groppa, G. (1985). In vitro antistreptococcal activity of the potassium-sparing diuretics amiloride and triamterene. Antimicrobial. Agents Chemother.28 (3):419-420 
23. Giunta, S., Galeazzi, L., Turchetti, G., Sampaoli, G., and Groppa, G. (1986). Effect of amiloride on the intracellular sodium and potassium content of intact Streptococcus faecalis cells in vitro. Antimicrob. Agents Chemother. 29(5): 958-959

24. Cohn, R.C., Rudzienski, L. and Putnam, R.W. (1992). In vitro antimicrobial activity of amiloride analogs against Pseudomonas. Chemotherapy.38(4):232-7.

25. World Health Organization Model List of Essential Medicines (2019). (https://apps.who.int/iris/bitstream/handle/10665/325771/WHO-MVP-EMP-IAU-2019.06eng.pdf?ua=1).

26. Kaila, K., and Vaughan-Jones, R. D. (1987). Influence of sodium-hydrogen exchange on intracellular pH, sodium and tension in sheep cardiac Purkinje fibres. J. physiol. 390: 93118. https://doi.org/10.1113/jphysiol.1987.sp016688

27. Mihaila, R.G. (2015). A minireview on NHE1 inhibitors. A rediscovered hope in oncohematology. Biomed. Pap. Med. Fac. Univ. Palacky Olomouc. Czech Repub. 159(4):519-26. doi: 10.5507/bp.2015.060.

28. Pires, D. E. V., Blundell T. L. and Ascher, D.B. (2015). pkCSM: Predicting Small-Molecule Pharmacokinetic and Toxicity Properties Using Graph-Based Signatures. J. Med. Chem. 58: 4066-4072.

29. Yang, H., Lou, C., Sun, L., Li, J., Cai, Y., Wang, Z., Li, W., Lio, G. and Tang, Y. (2019). admetSAR 2.0: web-service for prediction and optimization of chemical ADMET properties. Bioinformatics. 35 (6): 1067-1069.

30. SwissADME: a free web tool to evaluate pharmacokinetics, drug-likeness and medicinal chemistry friendliness of small molecules. Sci. Rep. (2017) 7:42717.

31. Banerjee, P., Eckert, A.O., Schrey, A.K. and Preissner, R. (2018). ProTox-II: a webserver for the prediction of toxicity of chemicals. Nucleic Acids Res. 246(W1):W257-W263. doi:10.1093/nar/gky318

32. Wiens, E.J., Winogrodzki, J.L., Resch, C.T., Orriss, G.L., Stetefeld, J., Dibrov, P. (2014). The C-terminal cytoplasmic portion of the NhaP2 cation-proton antiporter from Vibrio cholerae affects its activity and substrate affinity. Mol. Cell. Biochem., 389: 51-58.

33. Kim, D.E., Chiyian, D., Baker, D. (2004). Protein structure prediction and analysis using the Robetta server. Nucleic. Acids. Res.,32(Web Server issue):W526-W531. 
34. Delano, W.L., Lam, J.W. (2005). A communications tool for computational models. Abstr. Pap. Am. Chem. S. 230: U1371-U1372.

35. DeLano, W. L. (2002). Pymol: An open-source molecular graphics tool. CCP4 newsletter on protein crystallography. 40: 82-92

36. Wöhlert, D., Kühlbrandt, W., Yildiz, Ö. (2014). Structure and substrate ion binding in the sodium/proton antiporter PaNhaP. eLife. 3:03579. doi: 10.7554/eLife.03579

37. Lovell, S.C., Davis, I.W., Arendall III, W.B., de Bakker, P.I.W., Prisant, J.M.Word.M.G., Richardson, J.S., Richardson, D.C. (2002). Structure validation by Calpha geometry: phi, psi and C-beta deviation. Proteins: Struct. Funct. Genet. 50: 437-450.

38. Feig, M. (2016). Improvement of the local stereochemistry of protein structure models. J. Chem. Inf. Model. 56: 1304-1312.

39. Waterhouse, A., Bertoni, M., Bienert, S., Studer, G., Tauriello, G., Gumienny, R., Heer, F.T., De Beer, T.A.P., Rempfer, C., Bordoli, L., Lepore, R., Schwede, T. (2018).

SWISSMODEL: homology modelling of protein structures and complexes. Nucleic Acids Res. 46 (W1): W296-W303.

40. Wiederstein, M., \& Sippl, M. J. (2007). ProSA-web: interactive web service for the recognition of errors in three-dimensional structures of proteins. Nucleic acids Res. 35(Web Server issue), W407-W410. https://doi.org/10.1093/nar/gkm290

41. Trott, O. and Olson, A. J. (2010). AutoDock Vina: improving the speed and accuracy of docking with a new scoring function, efficient optimization, and multithreading. Journal of computational chemistry, 31(2), 455-461. https://doi.org/10.1002/jcc.21334.

42. Ghersi, D., and Sanchez, R. (2009). Improving accuracy and efficiency of blind proteinligand docking by focusing on predicted binding sites. Proteins. 74(2): 417-424. https://doi.org/10.1002/prot.22154

43. Pettersen, E.F., Goddard, T.D., Huang, C.C., Couch, G.S., Greenblatt, D.M., Meng, E.C. and Ferrin, T.E. (2004). UCSF Chimera--a visualization system for exploratory research and analysis. J. Comput. Chem. 25(13):1605-12.

44. Laskowski, R.A. and Swindells, M.B. (2011). LigPlot+: Multiple Ligand-Protein Interaction Diagrams for Drug Discovery. J. Chem. Inf. Model. 51(10): 2778-2786

45. Li, J.H., Cragoe, E.J. and Lindemann, B. (1985). Structure-activity relationship of amiloride analogs as blockers of epithelial Na channels: I. Pyrazine-ring modifications. J. Membrain Biol. 83: 45-56. https://doi.org/10.1007/BF01868737 
46. Matthews, H., Ranson, M., Tyndall, J.D. and Kelso, M.J. (2011). Synthesis and preliminary evaluation of amiloride analogs as inhibitors of the urokinase-type plasminogen activator (uPA). Bioorg. Med. Chem. Lett. 21: 6760-6766.

47. Sliwoski, G., Kothiwale, S., Meiler, J. and Lowe, E. W., Jr (2013).

Computational methods in drug discovery. Pharmacol Rev. 66(1): 334-395.

https://doi.org/10.1124/pr.112.007336.

48. Krieger, E., Joo, K., Lee, J., Lee, J., Raman, S., Thompson, J., Tyka, M., Baker, D., and Karplus, K. (2009). Improving physical realism, stereochemistry, and side-chain accuracy in homology modeling: Four approaches that performed well in CASP8. Proteins. 77 (9): 114122. https://doi.org/10.1002/prot.22570.

49. Mondol, T.K. (1990). Electron microscopic study of the polymyxin treated Vibrio cholerae cells. Z. Naturforsch.C., 45(7-8): 902-910.

50. Jo, S., Kim, T., Iyer, V.G., Im, W. (2008). CHARMM-GUI: A Web-based Graphical User Interface for CHARMM. J. Comput. Chem. 29: 1859-1865.

51. Qi, Y., Ingólfsson, H.I., Cheng, X., Lee, J., Marrink, S.J., Im, W. (2015). CHARMM-GUI Martini Maker for coarse-grained simulations with the Martini force field. J. Chem. Theory. Comput. 11:4486-4494.

52. Mark, J.A., Murtola, T., Schulz, R., P’all, S., Smith, J.C., Hess, B., Lindahl, E. (2015). GROMACS: High performance molecular simulations through multi-level parallelism from laptops to supercomputers. Software. X. 1-2: 16-25.

53. Pathak, R.K., Gupta, A., Shukla, R., Baunthiyal, M. (2018). Identification of new drug-like compounds from millets as Xanthine oxidoreductase inhibitors for treatment of Hyperuricemia: A molecular docking and simulation study. Comput Biol Chem. 76(32):41.

54. Vincent, B. C. et al. (2010). MolProbity: all-atom structure validation for macromolecular crystallography. Acta. Crystallogr. D. Biol. Crystallogr. 66(1): 12-21.

55. Kumar, S., \& Varela, M. F. (2012). Biochemistry of bacterial multidrug efflux pumps. International journal of molecular sciences, 13(4): 4484-4495.

56. Paulsen, I. T., Brown, M. H. and Skurray, R.A. (1996). Proton-dependent multidrug efflux systems. Microbiol. Rev. 60 (4): 575-608 
57. Minato, Y., Ghosh, A., Faulkner, J.W., Lind, J.E., Bartra,S.S., Plano,V.G., Jarrett, O.C., Hinnebusch,J., Winogrodzki, J., Dibrov, P., Häse C.C. (2013). $\mathrm{Na}^{+} / \mathrm{H}^{+}$antiport is essential for Yersinia pestis virulence. Infect. Immun., 81 (9): 3163-3172.

58. Guengerich F. P. (2011). Mechanisms of drug toxicity and relevance to pharmaceutical development. Drug metabolism and pharmacokinetics, 26(1): 3-14.

https://doi.org/10.2133/dmpk.dmpk-10-rv-062.

59. LiverTox: Clinical and Research Information on Drug-Induced Liver Injury [Internet].

Source Bethesda (MD): National Institute of Diabetes and Digestive and Kidney Diseases; 2012.

60. Lipinski, C. A. (2004). Lead- and drug-like compounds: the rule-of-five revolution. Drug Discov. Today. Technol. 1(4): 337-341. 